\title{
Evaluating the Ectasia Risk Score System in Cancelled Laser In Situ Keratomileusis Candidates
}

\author{
Mehrdad Mohamadpour ${ }^{1}$, MD; Masoud Khorrami-Nejad ${ }^{1,2}$, MS; Mohammad Yaser Kiarudi ${ }^{1}$, MD \\ Keivan Khosravi ${ }^{1}$, MD
}

${ }^{1}$ Translational Ophthalmology Research Center, Farabi Eye Hospital, Tehran University of Medical Sciences, Tehran, Iran ${ }^{2}$ School of Rehabilitation, Shahid Beheshti University of Medical Sciences, Tehran, Iran

ORCID:

Mehrdad Mohamadpour: https://orcid.org/0000-0002-9383-6362

\section{Abstract}

Purpose: To evaluate the ectasia risk score system in cancelled laser in situ keratomileusis (LASIK) candidates at an academic hospital.

Methods: LASIK candidates who had been cancelled by a surgeon considering the patient age, preoperative central corneal thickness, residual stromal bed thickness, or preoperative manifest refraction spherical equivalent were retrospectively reviewed, and their Randleman ectasia risk score system score was calculated.

Results: The mean ectasia score of 194 eyes (97 patients) was $4.5 \pm 2.67 ; 40$ (20.6\%), 46 (23.7\%), and 108 (55.7\%) eyes were classified as low-, moderate-, and high-risk eyes, respectively. The topography was abnormal in $69 \%$ of the patients. The mean manifest refraction spherical equivalent, central corneal thickness, and estimated residual stromal bed thickness were 4 (+0.50 to -15.50) diopters, 520 (439 to 608) $\mu \mathrm{m}$, and 312.38 (61.5 to 424.12$) \mu \mathrm{m}$, respectively. The main cause of cancellation in low- and moderate-risk patients (86 eyes) was the presence of unstable refractive error in the past year.

Conclusion: Although promising, some other criteria, such as stable refraction, should be added to this scoring system to achieve greater practicality since a main cause of cancelling LASIK candidates in this study was the presence of unstable refraction.

Keywords:

J Ophthalmic Vis Res 2020; 15 (4): 481-485

\section{INTRODUCTION}

Ectasia, progressive steepening, and thinning of the cornea are uncommon but serious

\section{Correspondence to:}

Mehrdad Mohammadpour, MD. Translational Ophthalmology Research Center, Farabi Eye Hospital, Tehran University of Medical Sciences

Email: mahammadpour@yahoo.com

Received: 10-06-2019 Accepted: 27-07-2020

\section{Access this article online}

Website: https://knepublishing.com/index.php/JOVR

DOI: 10.18502/jovr.v15i4.7788 complications of excimer laser corneal refractive surgery that reduce uncorrected and often corrected distance visual acuity (CDVA). They occur commonly after laser in situ keratomileusis (LASIK) and infrequently after photorefractive keratectomy (PRK). ${ }^{[1]}$ Because of the significant medical and legal consequences

This is an open access journal, and articles are distributed under the terms of the Creative Commons Attribution-NonCommercial-ShareAlike 4.0 License, which allows others to remix, tweak, and build upon the work non-commercially, as long as appropriate credit is given and the new creations are licensed under the identical terms.

How to cite this article: Mohamadpour M, Khorrami-Nejad M, Kiarudi MY Khosravi K. Evaluating the Ectasia Risk Score System in Cancelled Laser In Situ Keratomileusis Candidates. J Ophthalmic Vis Res 2020;15:481-485. 
of this complication, studies have focused on this issue. ${ }^{[2-9]}$

Ectatic changes can occur as early as one week after LASIK or be delayed for up to several years after the initial procedure. ${ }^{[10]}$ Histologic findings suggest that post-LASIK keratectasia results in collagen fibril thinning and a decreased interfibrillar distance within the residual stromal bed (RSB). ${ }^{[1]}$

Clinical and topographical findings of ectasia are often indistinguishable from those of keratoconus. ${ }^{[12]}$ To date, no method can definitively diagnose patients with ectasia. A practical task for clinicians is to improve the sensitivity of screening methods for identifying patients with mild keratoconus to prevent iatrogenic keratectasia. Randleman et $\mathrm{al}^{\left[{ }^{[1]}\right.}$ developed a scoring system to evaluate the risk of ectasia after LASIK considering some parameters - such as preoperative topography, RSB thickness, age, preoperative corneal thickness, and degree of myopia - to better identify patients with a high risk for ectasia. They concluded that no single characteristic identifies all at-risk patients. Instead, various factors should be considered in a weighted fashion. For all patients, special emphasis should be placed on the topographic pattern, and factors in addition to the inferior-superior value or computer-generated indices should be considered in the screening. For young patients, heightened scrutiny is warranted, and other aspects of their preoperative evaluation, particularly topographic patterns and refractive stability, should be within normal limits. The intraoperative corneal thickness should be measured if the variability of flap thickness is likely to put a patient at risk for ectasia. In the initial series, this scoring system showed a high sensitivity and specificity. Subsequently, another study validated it and noted the ectasia risk score system (ERSS) to be a valid and effective method for detecting the eyes with ectasia after LASIK. ${ }^{[13]}$

This study was aimed at retrospectively evaluating the ERSS score in candidates for refractive surgery who were cancelled by a surgeon. We calculated the risk score of cancelled LASIK candidates to evaluate the efficacy of ERSS for the preoperative screening.

\section{METHODS}

Medical records of candidates for refractive surgery who had been cancelled by a surgeon (MM) at
Farabi Eye Hospital, Tehran University of Medical Sciences, Tehran, Iran, between 2011 and 2015 were reviewed. Causes of cancellation of these candidates were based on conventional and individual criteria, such as unstable refraction, defined as an increase in the spherical or cylindrical refractive error $>0.5$ diopters (D) in the past year, age $<9$ years, or suspected or abnormal topographical patterns, such as inferior steepening $>1.4 \mathrm{D}$, central corneal thickness $<480 \mu \mathrm{m}$, RSB $<250 \mu \mathrm{m}$, or CDVA $<20 / 30$. The exclusion criteria were a history of refractive or cataract surgery, keratoconus, collagen vascular disease, and diabetic retinopathy.

Data of all patients, including the age, sex, preoperative manifest refraction spherical equivalent, central corneal thickness, topographic pattern, and predicted RSB thickness were evaluated, and their Randleman ectasia risk factor score was calculated. Based on the Randleman ERSS, as described previously, ${ }^{[1]}$ a cumulative ectasia risk score was calculated for all patients. Central corneal and RSB thicknesses were measured using a Pentacam topographer (Oculus, Wentzler, Germany). Regarding the cumulative points, risk categories were as follows: 0-2 points, low risk; 3 points, moderate risk; and 4 points, high risk.

\section{RESULTS}

A total of 97 patients (194 eyes) were included in this study, with the mean age of 26.4 years (range: 18-50 years). Sex distribution was approximately equal (48 women and 49 men).

According to the Randleman ERSS for preoperative refractive surgery, 40 (20.6\%), 46 (23.7\%), and 108 (55.7\%) eyes had low-, moderate-, and high-risk scores, respectively. The mean score was $4.5 \pm 2.67$. The mean manifest refraction spherical equivalent, central corneal thickness, and estimated RSB thickness were 4 ( +0.5 to -15.5$)$ D, 520 (439 to 608) $\mu \mathrm{m}$, and 312.38 (61.5 to 424.12) $\mu \mathrm{m}$, respectively (Table 1$)$. Refractive astigmatism ranged from 0.5 to $6.25 \mathrm{D}$. Corneal astigmatism ranged from 0.04 to $4.90 \mathrm{D}$. Internal astigmatism ranged from 0 to $2.25 \mathrm{D}$. Unstable refraction was found in 86 (44.3\%) eyes.

Table 2 shows the topographic characteristics of the patients. The symmetrical (normal) pattern, asymmetrical bow tie, inferior steepening 


\begin{tabular}{|c|c|c|c|c|c|}
\hline \multirow[t]{2}{*}{ Parameter } & \multicolumn{5}{|c|}{ Points } \\
\hline & 4 & 3 & 2 & 1 & 0 \\
\hline Topography & $\begin{array}{c}\text { Abnormal } \\
\text { topography }\end{array}$ & INF steep/SRA & & ABT & Normal/SBT \\
\hline RSB $(\mu)$ & $<240$ & 240 to 259 & 260 to 279 & 280 to 299 & $\geq 300$ \\
\hline Age (yrs) & & 18 to 21 & 22 to 25 & 26 to 29 & $\geq 30$ \\
\hline $\mathrm{CT}(\mu)$ & $<450$ & 451 to 480 & 481 to 510 & & $\geq 510$ \\
\hline MRSD (D) & $>-14$ & $>-12$ to -14 & $>-10$ to -12 & $>-8$ to -10 & $>-8$ or less \\
\hline
\end{tabular}

Low risk (0-2 points), moderate risk (3 points), high risk ( $\geq 4$ points)

ABT, asymmetric bowtie; CT, corneal thickness; D, diopters; INF steep, inferior steepening pattern; MRSE, manifest refraction spherical equivalent; RSB, residual stromal bed thickness; SBT, symmetric bowtie; SRA, skewed radial axis; Yrs, years

Table 2. Characteristics of 97 patients (194 eyes)

\section{Features}

Age (years)

Gender Male Female

MRSE (D)

$\operatorname{CCT}(\mu)$

$\operatorname{RSB}(\mu)$
Mean (range)

26.44 (18 to 50$)$

49 (50.5\%) $48(49.5 \%)$

4 (0.5 to 15.5)

520 (439 to 608$)$

312.38 (61.5 to 424.12$)$

CCT, central corneal thickness; D, diopters; MRSE, manifest refraction spherical equivalent; RSB, residual stromal bed thickness

or skewed radial axis, and other abnormal topographic (pellucid) patterns were seen in 65 (33.51\%), 87 (44.84\%), 39 (20.1\%), and 3 (1.54\%) eyes, respectively.

\section{DISCUSSION}

In our study, a significant number of patients (86 eyes, $43.7 \%$ ) who were not scheduled for LASIK due to unstable refraction in the past year had a low or moderate ERSS score (1-3). Therefore, this method, which is applied for categorizing and assessing the risk of ectasia, should be modified in consideration of unstable refractive errors.

Reports on ERSS are incongruent. ${ }^{[13-16]}$ Previously, Randelman et al stated that this system, which was developed from case reports of ectasia, was more sensitive compared to traditional screening strategies. In a subsequent study, Randelman et al validated their risk scoring system by applying it on 50 previously unpublished ectasia cases matched to 50 normal eyes. The sensitivity and specificity of their scoring system for the initial and comparison populations were $91 \%$ and $92 \%$, respectively. ${ }^{[13]}$

Binder et $\mathrm{al}^{[15]}$ retrospectively reviewed a surgeon's LASIK database to assess Randleman ectasia risk scores in eyes with normal preoperative topography. Risk scores of 5 or more, 4 or more, and 3 or more were found in 35 (2.1\%), 92 (5.4\%), and 208 (12.2\%) eyes with a normal topography, respectively. None of these eyes developed ectasia. In their evaluation, three eyes of two patients in the entire database of 9,813 myopic eyes with variable follow-up periods developed ectasia. They noted that with this risk score system, $5.4 \%$ of eyes with 4 or more points would have been eliminated from LASIK surgery, and an additional $6.8 \%$ of eyes with a score of 3 indicating a "moderate risk" would have required the surgeon to exercise caution. Therefore, they concluded that in the eyes with normal preoperative topographies, this scoring system may not accurately predict an increased risk for developing postoperative LASIK ectasia. This is consistent with our findings of a significant number of patients at a high risk whom the 
Table 3. Topographic patterns of 194 eyes of 97 patients

Topographic pattern

Number (Percentage)

Normal/symmetrical

65 (33.51)

Asymmetric bowtie

87 (44.84)

INF steep/SRA

39 (20.11)

Abnormal

$3(1.54)$

INF Steep/SRA, topographic pattern with inferior steepening and/or a skewed radial axis

surgeon cancelled, while the risk score was low or moderate with ERSS.

Chan et al ${ }^{[14]}$ retrospectively evaluated ERSS in 36 eyes with post-LASIK ectasia. A low risk was seen in $25 \%$ of eyes. They reported the sensitivity of this method to be only $56 \%$ and concluded that ERSS can miss a significant proportion of patients at risk of ectasia. Randleman et $\mathrm{a}^{[1]}$ reported that unstable refractions may predict corneal ectasia after refractive surgery. This study suggests that other criteria, such as stable refraction, should be added to this scoring system for increased practicality since a main cause of cancelled LASIK candidates in this study was unstable refraction.

Hodge et $\mathrm{al}^{[16]}$ presented a case of unilateral keratectasia in a laser refractive surgery patient. LASIK was performed in the first eye, but because of the difficulty in lifting the femtosecond-created cap in the fellow eye, PRK was performed in that eye. In their report, the eyes had no risk factors for keratectasia and identical low Randleman ERSS scores. According to them, the procedure of elevating the cap had a weakening effect.

Consistent with Sorkin et al's study, ${ }^{[17]}$ a highly prevalent risk factor in our study was suspected and abnormal topographic patterns were found in approximately $64 \%$ of patients. This is consistent with former reports. Nearly $50 \%$ of ectasia cases in Randleman et al's study and 69\% in Chan et al's study had abnormal topographies. ERSS relies exclusively on Placido-based images. Recent topographic systems apply other corneal imaging, including Orbscan II and Pentacam imaging. The limitations of ERSS include starting keratoconus from the posterior portion and the lack of assessment of posterior elevation.

Another factor not included in our study for ERSS was unstable refraction. Randleman et $\mathrm{al}^{\left[{ }^{[1]}\right.}$ considered refractive instability in borderline cases that could increase the risk of ectasia. We defined it as a spherical or cylindrical refractive error $>0.5 \mathrm{D}$ in the past year and found it in $86(44.3 \%)$ eyes. This factor may be paramount for an effective refractive surgical screening.

Dawson et al evaluated the histopathology and ultrastructure of the corneas developing ectasia after LASIK or PRK and found no significant differences in any of the measurements in the LASIK flap or interface wound; however, the ultrastructure of RSB significantly differed between the ectatic and non-ectatic regions. The primary effect of the biomechanical failure process involves the RSB (42\% thickness reduction) compared to the LASIK flap or hypocellular primitive stromal scar. ${ }^{[18]}$ In this regard, preservation of at least a $250-\mu \mathrm{m}$ thickness in the central stromal bed after ablation is important for the prevention of ectasia, ${ }^{[19]}$ although the suggested range of minimum RSB varies from 200 to $318 \mu \mathrm{m} .{ }^{[20,21]}$ However, keratectasia can occur after LASIK with an RSB thickness of $>250$

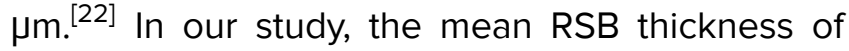
cancelled patients was $312 \mu \mathrm{m}$ above the widely accepted $250 \mu \mathrm{m}$. Moreover, in Chan et al's study, the average RSB was $>250 \mu \mathrm{m} .{ }^{[14]}$ Therefore, it cannot be an isolated risk factor.

We suggest considering refractive stability as a factor with a significant weight in a modified scoring system for the preoperative screening for ablative refractive surgery. Validation of other possible values, such as the degree of astigmatism, between eye topographic asymmetry, and family history of keratoconus should be evaluated. Moreover, studies should include a control group comprising the eyes that have undergone LASIK at the same interval. In conclusion, Randleman ERSS, although promising, is yet to be validated with a population of ectasia cases and controls.

\section{Financial Support and Sponsorship}

None. 


\section{Conflicts of Interest}

\section{There are no conflicts of interest.}

\section{REFERENCES}

1. Randleman JB, Woodward M, Lynn MJ, Stulting RD. Risk assessment for ectasia after corneal refractive surgery. Ophthalmology 2008;115:37-50.

2. Giri P, Azar DT. Risk profiles of ectasia after keratorefractive surgery. Curr Opin Ophthalmol 2017;28:337-342.

3. Comaish IF, Lawless MA. Progressive post-LASIK keratectasia: biomechanical instability or chronic disease process? J Cataract Refract Surg 2002;28:2206-2213.

4. Kohnen T. latrogenic keratectasia: current knowledge, current measurements. J Cataract Refract Surg 2002;28:2065-2066.

5. Binder PS. Analysis of ectasia after laser in situ keratomileusis: risk factors. J Cataract Refract Surg 2007;33:1530-1538.

6. Saad A, Binder PS, Gatinel D. Evaluation of the percentage tissue altered as a risk factor for developing post-laser in situ keratomileusis ectasia. J Cataract Refract Surg 2017;43:946-951.

7. Randleman JB. Post-laser in-situ keratomileusis ectasia: current understanding and future directions. Curr Opin Ophthalmol 2006;17:406-412.

8. Belin MW, Ambrósio R. Analyzing tomographic corneal elevation for detecting ectasia. In: Keratoconus. Cham, Switzerland: Springer; 2017:65-75.

9. Mohammadpour M. Risk for ectasia with LASIK. J Cataract Refract Surg 2008;34:181-182.

10. Rao SN, Epstein RJ. Early onset keratectasia following laser in situ keratomileusis: case report and literature review. J Refract Surg 2002;18:177-184.

11. Meghpara B, Nakamura $H$, Macsai M, Sugar J, Hidayat A, Yue BYJT, et al. Keratectasia after laser in situ keratomileusis, a histopathologic and immunohistochemical study. Arch Ophthalmol 2008;126:1655-1663.

12. Binder PS. Ectasia after laser in situ keratomileusis. $J$ Cataract Refract Surg 2003;29: 2419-2429.

13. Randleman JB, Trattler WB, Stulting RD. validation of the ectasia risk score system for preoperative laser in situ keratomileusis screening. $A m \mathrm{~J}$ Ophthalmol 2008;145:813-818.

14. Chan CC, Hodge C, Sutton G. External analysis of the Randleman ectasia risk factor score system: a review of 36 cases of post LASIK ectasia. Clin Experiment Ophthalmol 2010;38:335-340.

15. Binder PS, Trattler WB. Evaluation of a risk factor scoring system for corneal ectasia after LASIK in eyes with normal topography. J Refract Surg 2010;26:241-250.

16. Hodge C, Lawless M, Sutton G. Keratectasia following LASIK in a patient with uncomplicated PRK in the fellow eye. J Cataract Refract Surg 2011;37:603-607.

17. Sorkin N, Kaiserman I, Domniz Y, Sela T, Munzer G, Varssano D. Risk assessment for corneal ectasia following photorefractive keratectomy. J Ophthalmol 2017;2017:2434830. DOI: 10.1155/2017/2434830.

18. Dawson DG, Randleman JB, Grossniklaus HE, O'Brien TP, Dubovy SR, Schmacket I, al. Corneal ectasia after excimer laser keratorefractive surgery: histopathology, ultrastructure, and pathophysiology. Ophthalmology 2008;15:2181-2191.

19. Javadi MA, Mohammadpour M, Rabei HM. Keratectasia after LASIK but not after PRK in one patient. J Refract Surg 2006;22:817-820.

20. Wang Z, Chen J, Yang B. Posterior corneal surface topographic changes after laser in situ keratomileusis are related to residual corneal bed thickness. Ophthalmology 1999;106:406-409.

21. Esquenazi S. Comparison of laser in situ keratomileusis and automated lamellar keratoplasty for the treatment of myopia. J Refract Surg 1997;13:637-643.

22. Ou RJ, Shaw EL, Glasgow BJ. Keratectasia after laser in situ keratomileusis (LASIK): evaluation of the calculated residual stromal bed thickness. Am J Ophthalmol 2002;134:771-773. 